\title{
Editorial
}

Conflict theory and conflict intervention can be explored using a wide range of perspectives, from a focus on different specialisms, through theory, research and to theory applied to practice. We welcome the contributors to this issue from many parts of the world, covering a wide range of mediation themes and topics. The authors in this issue examine conflict with a focus on a variety of different fields of knowledge which are the bases for the articles.

In this issue, Aytekin Cantekin presents and critiques conflict "ripeness" or "readiness" theories, concepts that have been helpful as analytic tools in the world of peace-making. His article, "Ripeness and Readiness Theories in International Conflict Resolution" argues that "...using readiness theory (first) to understand each party and its positions separately, then using ripeness theory to map the bilateral coordination can be a better way to grasp basic foundations and change dynamics of the conflict to catch the ripe moment..." for conflict intervention in international conflicts.

In her article, "Promoting Workplace Mediation in Ireland: Key Recommendations," Oksana Kokaylo examines workplace mediation in Ireland through a review of Irish law, policy and practice while detailing the benefits and exploring the barriers for companies, employees and employers to engaging in mediation. She reports on a survey of practitioner workplace mediators in Ireland and concludes by making key recommendations for the promotion of workplace mediation. Oksana states: "It is important to encourage, support and promote workplace mediation in Ireland at every level including the State, the Judiciary, professional bodies, private and public organisations."

Greg Rooney traces the development of commercial mediation in Australia in a detailed and reflective article, "The Rise of Commercial Mediation in Australia - Reflections and the Challenges ahead." He examines why mediation works, the source of the mediator's power and why people get trapped in conflict. He argues that we live in a fast changing commercial world with a high level of interconnectedness and concludes that this ".... adds a significant layer of uncertainty and unpredictability to any commercial enterprise. How people relate to each other and their ability to communicate and resolve differences are crucial to the proper functioning of this modern complex society."

In his article, "Conflict Resolution within a Buddhist Context", Michael Tophoff presents Buddhist philosophy as a viable mind set for conflict resolution. He argues that this ancient belief system offers tools for mediators that are drawn from a guiding belief system. He writes that the "virtues of nonviolence, compassion, wisdom, empatby and benevolence, facilitate impulse regulation" are "the Buddhist based prerequisites of mediation." He espouses mindfulness as a means of building a "respectful connection with the clients", and "can influence the climate between them."

In her article, "Finding Fairness in a high volume Statutory ADR environment: Observations from an Australian Work Cover conciliation service." Penny Webster examines the work of the Accident Compensation Conciliation Service, in Victoria, Australia. She explores how well the ACCS is achieving the Workplace Injury Rehabilitation and Compensation Act 2013 key goals, fairness, 
informality, quickness and efficiency. Webster challenges the view "that participant satisfaction is a valid measure of success of a conciliation process." She presents statistics that show a "widening gap between the numbers of cases allocated and the numbers resolved" and advocates developing assessment criteria for conciliation processes as a future industry wide project "essential for the credibility of mandatory statutory ADR." The articles in this issue address a wide range of topics and perspectives, offering theory, practice and research applied in a variety of fields, meeting the goal of the journal to assist those who are working towards a more collaborative world.

\section{Delma Sweeney}

